\title{
PEMBENAHAN SISTEM INVENTORI UKM SUMBER BERKAT MANDIRI, BLITAR, JAWA TIMUR
}

\author{
Tuti Hartani $^{1}$, Benedicta D. Muljani ${ }^{2}$, Eric Sulindra ${ }^{3}$, dan Philipus Suryo Subandoro ${ }^{4}$ \\ Universitas Katolik Widya Mandala Surabaya \\ tuti_hartani@ukwms.ac.id,bene@ukwms.ac.id,eric@ukwms.ac.id,dan \\ philipus@ukwms.ac.id
}

\begin{abstract}
ABSTRAK
UKM Sumber Berkat Mandiri sebagai Mitra Tim Abdimas selama ini menggunakan "sistem manajemen warung" dalam menjalankan bisnis di mana hampir seluruh urusan dikerjakan secara perorangan. Manajemen tersebut menyebabkan kurang optimalnya sistem administrasi, terutama dalam hal pencatatan aset, berdampak pada over stock dan kerugian lain. Secara umum, permasalahan yang dihadapi mitra adalah belum adanya sistem administrasi terpadu untuk membantu pelaksanaan proses bisnis Mitra dan belum adanya sistem manajemen aset yang baik. Karena itu, tim abdimas membantu mitra untuk membenahi sistem inventori mitra, juga mengembangkan kemampuan manajerial Mitra melalui pengembangan keterampilan bagi Mitra dalam hal kepemimpinan, etika profesi, manajemen waktu, layanan prima, dan keterampilan interpersonal. Metode pelaksanaan kegiatan Abdimas ini dilakukan dalam 4 (empat) tahap. Tahap pertama survey untuk mengidentifikasi kebutuhan mitra; tahap kedua pemberian materi pelatihan; tahap ketiga penugasan kepada mitra terkait inventori barang yang dijual; tahap keempat sharing atas pelatihan yang telah didapatkan dan pendampingan penggunaan aplikasi inventory management. Luaran kegiatan pengabdian ini adalah buku panduan kerja yang dapat digunakan oleh mitra dalam mengimplentasikan aplikasi inventory management.
\end{abstract}

\section{Kata Kunci: UKM, pencatatan aset, aplikasi inventory management}

\begin{abstract}
A Small-Medium Enterprise unit, Sumber Berkat Mandiri, as the partner of this social and community service activity, has been using "sistem manajemen warung" in doing the business, in which almost all management activities are done in 'one man show' mode. This management style causes lacking in administration system optimality, especially in inventory record. The style has created over stock problem and other losses. In general, the partner's major problem is the absence of integrated administration system for the business process and lacking of good inventory system. Therefore, the social and community service team helps the partner to implement an application for the inventory record and also develop the partner's managerial skills through leadership training, professional ethics training, time management and service excellence trainings, as well as interpersonal skills training. The methods used in helping the partner are divided into 4 (four) phases. The first phase is doing a survey to get the partner's needs; the second phase is giving the trainings; the third phase is asking the partner to record the inventory of all items in the partner's warehouse; and the fourth phase is getting the partner's feedback after receiving all the trainings and guiding the partner in implementing inventory management application. The result of this activity is a manual book for the partner to implement the inventory management application.
\end{abstract}

Keywords: Small-medium enterprise unit, inventory record, inventory management application 


\section{PENDAHULUAN}

Pemilik Sumber Berkat Mandiri yang menjadi mitra adalah pengelola Usaha Kecil dan Menengah (UKM) yang berlokasi di Blitar, Jawa Timur. Pada awalnya, mitra adalah pemilik merek jamu untuk ternak dengan nama Berkat Mandiri. Selanjutnya, mitra mengembangkan usaha dengan menjual alat-alat peternakan, pertanian modern, dan teknik dengan perkiraan jumlah jenis barang yang dijual lebih kurang 350 jenis. Mekanisme pemasaran yang dilakukan oleh mitra pada awalnya adalah melayani pembeli langsung di toko. Pandemi COVID-19 semakin memantapkan langkah mitra untuk melakukan pemasaran melalui marketplace seperti Tokopedia, Shopee, dll sehingga mampu menjangkau konsumen lebih luas.

Selama dua tahun beroperasi, pada tahun 2019 mitra mencatat omzet penjualan sebesar Rp 2.000.000.000,00 (dua miliar rupiah). Omzet ini meningkat sebesar 20\% menjadi Rp 2.400.000.000,00 (dua miliar empat ratus juta rupiah) pada tahun 2020. Peningkatan omzet tersebut perlu dibarengi dengan pembenahan pada sistem administrasi secara terpadu untuk semakin mempermudah mitra dalam mengelola sumber daya manusia maupun barang yang dimiliki. Salah satu contoh dampak yang dialami oleh Mitra karena tidak adanya sistem administrasi yang terpadu kesulitan yang dialami mitra untuk mengidentifikasi letak dan jumlah barang dagangan yang dimiliki. Sistem administrasi yang belum sempurna menyebabkan mitra kesulitan untuk mengetahui jumlah barang yang tersedia di gudang sehingga mitra memilih untuk overstock/membeli dalam jumlah banyak agar dapat memenuhi permintaan pelanggan. Mitra menggunakan istilah "model manajemen warung" untuk menggambarkan mekanisme kerja yang selama ini dilakukan.

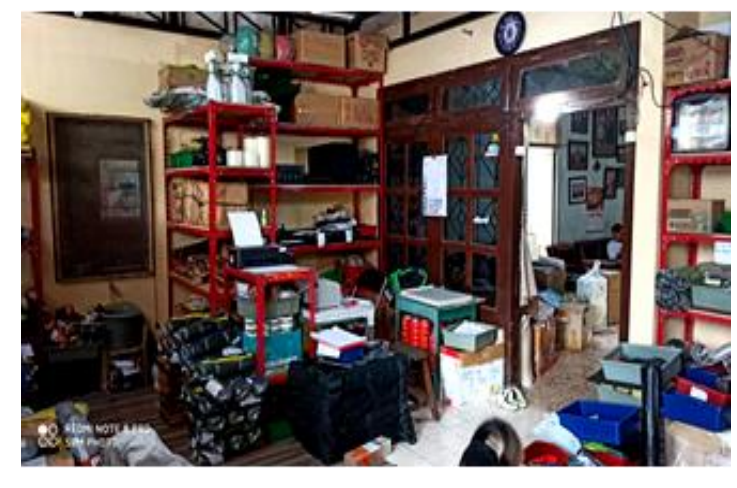

Pada wawancara awal, mitra mengungkapkan harapan untuk mendapatkan bantuan pendampingan terkait pembenahan sistem inventory serta pelaksanaannya. Artinya, Mitra mengharapkan adanya pendampingan dalam penataan kegiatan administrasi tersebut sehingga mitra bisa mengetahui inventori barang dagangannya secara tepat.

\section{METODE PELAKSANAAN}


Kegiatan pengabdian pada masyarakat PEMBENAHAN SISTEM INVENTORY UKM SUMBER BERKAT MANDIRI BLITAR JAWA TIMUR ini terbagi dalam 4 kegiatan utama yang terdiri dari:

\section{Tahap Survey Kebutuhan Mitra}

Tim pengusul melakukan survey dengan melakukan wawancara secara daring untuk mengetahui permasalahan dan kebutuhan mitra. Hasil survey menunjukkan bahwa mitra melakukan bisnisnya dengan cara one man show, dengan gaya manajemen warung yaitu semua keputusan dan tindakan dilakukan sendiri oleh pimpinan yang juga merupakan pemilik, serta mitra tidak memiliki data inventori yang akurat sehingga untuk mengetahui ketersediaan barang hanya mengandalkan ingatan pemilik. Mitra membutuhkan pembenahan dalam sistem inventorinya.

\section{Tahap Pemberian Materi}

Tim pengusul abdimas memberikan pembekalan materi berupa Pelatihan Layanan Prima dan Etika Kerja, Pelatihan Komunikasi Interpersonal, Manajemen Waktu, dan Kepemimpinan, serta Pelatihan Penggunaan Aplikasi Inventory Management, yang disampaikan melalui ceramah dan workshop kepada mitra yaitu pimpinan dan karyawan di UKM Sumber Berkat Mandiri Blitar.

2. Tahap Penugasan

Tim pengusul abdimas menugasi mitra untuk melakukan pemetaan terhadap jenis barang dan jumlah masing-masing barang yang ada di Gudang untuk dimasukkan ke dalam aplikasi Inventory management.

\section{Tahap Sharing dan Pendampingan}

Setelah menerima semua materi pelatihan, mitra diminta untuk sharing atas semua pelatihan yang telah diberikan dengan menggunakan panduan pertanyaan refleksi. Pendampingan oleh tim pendamping dilakukan terutama pada penggunaan aplikasi Inventory Management dengan harapan masalah yang muncul dapat dicarikan solusi oleh tim pendamping.

\section{HASIL DAN PEMBAHASAN}

Kegiatan yang dilakukan dalam Pengabdian pada masyarakat ini adalah pemberian pelatihan kepada mitra. Ada tiga jenis pelatihan yang diberikan kepada mitra yaitu Pelatihan Layanan Prima dan Etika Kerja; Pelatihan Komunikasi Interpersonal, Manajemen Waktu, dan Kepemimpinan; serta Pelatihan Penggunaan Aplikasi Inventory Management. Bentuk 
pelatihan adalah ceramah, pemutaran video, sharing pengalaman peserta selama bekerja dan beraktivitas di UKM Sumber Berkat Mandiri, serta pemberian contoh penggunaan aplikasi inventori yang sesuai dengan kebutuhan di UKM Sumber Berkat Mandiri. Semua pelatihan ini dilakukan melalui moda Zoom.

Berikut adalah penjelasan masingmasing pelatihan yang diberikan kepada mitra:

\section{Pelatihan Layanan Prima dan Etika}

\section{Kerja}

Tujuan pelatihan ini adalah agar karyawan di UKM Sumber Berkat Mandiri dapat melakukan pelayanan sebaik mungkin kepada para pelanggan berdasarkan prinsip 6 A yaitu Ability (kemampuan), Attitude (sikap), Appearance (penampilan), Attention (perhatian), Action (tindakan), Accountability (tanggungjawab), sehingga pelanggan menjadi merasa puas (Sampson, 2003). Harapannya, para karyawan dan juga pimpinan di UKM Sumber Berkat Mandiri dapat mengambil manfaat dari pentingnya memberikan Layanan Prima yaitu salah satunya untuk upaya meningkatkan kualitas pelayanan perusahaan kepada para pelanggan atau masyarakat, serta dapat menjadi acuan untuk pengembangan penyusunan standar pelayanan di perusahaan tersebut. Standar pelayanan dapat diartikan sebagai tolok ukur atau patokan yang digunakan untuk melakukan pelayanan dan juga sebagai acuan untuk menilai kualitas suatu

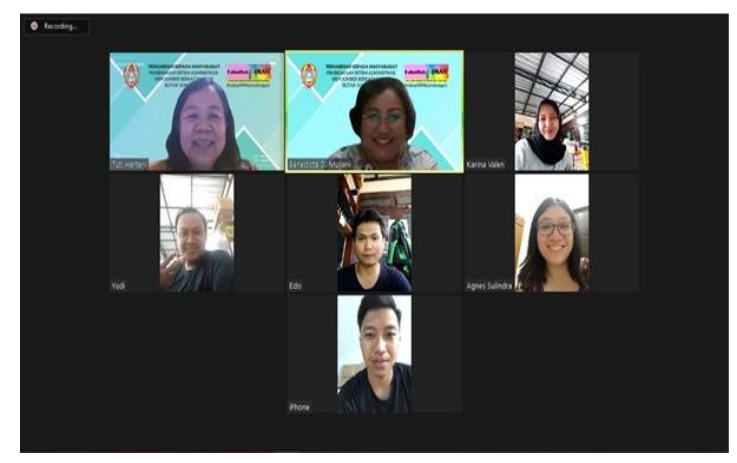

pelayanan.

Disamping itu, pemahaman terhadap Etika Kerja (Yuwono, 2011) dapat memberikan penguatan pada peserta bahwa sikap atau attitude yang mereka tunjukkan dalam memberikan pelayanan terhadap pelanggan selalu dilandasi oleh visi, misi dan tujuan perusahaan, berorientasi pada budaya peningkatan mutu kinerja, saling menghormati sesama karyawan, kerjasama, disiplin dan menjunjung tinggi tanggung jawab serta kejujuran.

\section{Pelatihan Komunikasi Interpersonal,} Manajemen Waktu, dan

\section{Kepemimpinan}

Tujuan pelatihan ini adalah agar karyawan di UKM Sumber Berkat Mandiri dapat lebih memahami dan menerapkan prinsip-prinsip komunikasi interpersonal, mengatur waktu dengan lebih baik, dan 
juga menjadi pemimpin diri sendiri. Halhal ini diharapkan dapat membantu peserta pelatihan lebih sukses dalam menjalani banyak aspek kehidupan, seperti karir, finansial, keluarga, dan lainnya.

Dalam pelaksanaan pelatihan ini, mula-mula peserta diminta untuk lebih mengenali diri dan karakter yang ingin dicapai serta merefleksikan relasinya dengan orang lain, terutama dengan rekan kerja. Dengan berbagai ilustrasi, peserta diajak memahami bahwa setiap orang bisa memandang suatu hal yang sama dengan perspektif yang berbeda-beda. Dengan demikian, peserta diharapkan bisa menjadi manusia yang lebih luwes untuk memandang hal-hal di sekitar kita dan bisa memahami orang lain.

Kemudian, peserta mendapatkan materi tentang analogi rekening tabungan emosional. Ketika kita membuat seseorang senang, itu artinya kita sedang "menabung". Ketika suatu saat kita membuat orang tersebut kurang senang, artinya kita sedang "menarik" saldo tabungan kita. Jika saldo sampai tipis atau habis, orang tersebut akan marah atau terluka. Dengan analogi ini, kita belajar untuk sering-sering "menabung" emosi ke orang lain, sehingga ketika kita tiba-tiba menarik saldo, orang tersebut tidak akan sampai sakit hati atau marah. Peserta diingatkan kembali untuk rajin-rajin menabung emosi ke orang lain, walau di tengah kesibukannya.

$$
\text { Pelatihan dilajutkan dengan }
$$
pembahasan tentang penggunaan manajemen waktu. Pembahasan ini dibantu dengan ilustrasi diagram waktu: penting, mendesak, tidak penting, dan tidak mendesak (Haynes, 1994). Hal yang penting dan mendesak seperti hal darurat, janji, perbaikan hal penting dilakukan dulu. Jika sudah selesai, peserta diharapkan bisa melakukan hal yang penting dan tidak mendesak, seperti menjalin relasi, membeli stok barang yang mendesak dan/atau hal-

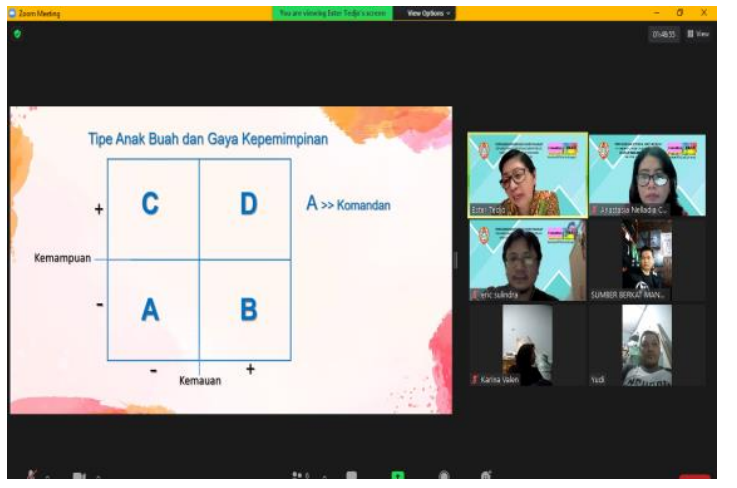

hal yang mendesak tapi tidak penting, baru hal-hal yang tidak penting dan tidak mendesak.

Pelatihan kemudian dilanjutkan dengan membahas tentang gaya kepemimpinan dan tipe anak buah. Jika anak buah adalah tipe orang yang kemampuan dan kemauan untuk belajar kurang, pimpinan bisa memimpin dengan gaya komandan. Jika anak buah adalah tipe orang yang mau belajar namun kemampuan kurang, pemimpin bisa memimpin dengan Jurnal Sekretari | Vol. 8 No. 2 | Juni 2021 
gaya guru. Jika anak buah adalah orang yang kemampuannya bagus namun memiliki kemauan untuk belajar yang kurang, pemimpin bisa mengadopsi gaya ulama (memberi nasihat). Jika anak buah adalah tipe yang memiliki kemampuan dan kemauan belajar yang bagus, gaya kepemimpinan yang digunakan sebaiknya adalah gaya konsultan.

\section{Pelatihan Penggunaan}

Aplikasi

\section{Inventory Management}

Tujuan pelatihan ini adalah agar pimpinan dan karyawan di UKM Sumber Berkat Mandiri mampu melakukan pengawasan dan mengontrol inventory barang dagangannya. Inventory atau persedian merupakan hal yang sangat penting dan fundamental dalam suatu organisasi. Menurut Rajeev (2008) dalam Jappy \& Koan (2014), Inventory merupakan bagian

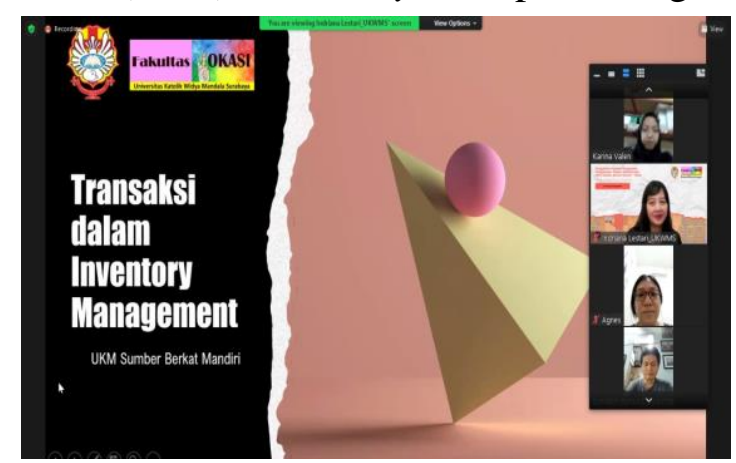

yang sangat signifikan dari aset lancar suatu organisasi, baik yang bergerak di bidang barang maupun jasa, baik skala kecil, menengah maupun besar. Hal ini menunjukkan bahwa Inventory merupakan salah satu faktor yang menentukan kelancaran produksi dan penjualan. Untuk itu, penting bagi, penting bagi UKM Sumber Berkat Mandiri melakukan pengelolaan inventory secara tepat.

Dengan adanya aplikasi inventori itu UKM Sumber Berkat Mandiri memiliki catatan detil mengenai macam dan jumlah serta lokasi semua item dagangan yang dimilikinya.

Dalam pelatihan itu pemateri menjelaskan cara-cara untuk mengunduh aplikasi, membuat akun, menambah collaborator, melakukan transaksi (realtime) dan mengolah data. Aplikasi inventory management yang dipresentasikan kepada UKM Sumber Berkat Mandiri merupakan aplikasi yang ada di play store. Jadi sebelum memulai masuk ke pelatihan, pemateri meminta kepada peserta untuk mengunduh aplikasi tersebut. Ada peserta yang bisa mengunduh karena menggunakan dua gadget, namun ada juga yang belum bisa karena smartphonenya dipakai untuk mengikuti zoom pelatihan.

Aplikasi inventory management memiliki keunggulan-keunggulan yang dapat dimanfaatkan oleh UKM Sumber Berkat Mandiri seperti dapat melakukan tugas inventori secara bersama-sama sebagai satu tim karena ada fungsi kolaborasi. Pemilik aplikasi bisa mengatur person yang masuk dalam tim yang bisa mengakses atau mengisi inventori di 
bagian yang dikehendaki pemilik. Pilihan yang tersedia product, transaction, dan collaborator. Kelebihan lainnya adalah penggunaan $Q R$ Code. $Q R$ Code bisa dipakai untuk menambah user. Aplikasi ini juga dilengkapi dengan fungsi scan barcode sehingga pemilik bisa lebih praktis dalam mencatat dan memasukan informasi mengenai jumlah barang yang akan diinvetori. Penggunaannya pun relatif mudah dan sederhana. Bahkan dengan mengubah mode dari gratis menjadi berlangganan untuk aplikasi ini maka pemilik bisa mendapatkan banyak manfaat seperti bisa mengunduh hasil inventori dalam format excel.

Setelah mengikuti setiap pelatihan, para peserta diminta untuk mengisi refleksi yang tujuannya adalah untuk membantu mereka memahami materi dan mencoba praktik dalam aktivitas pekerjaan mereka sehari-hari.

Hasil kegiatan pengabdian ini adalah sebuah buku Panduan Kerja yang dapat digunakan oleh mitra dalam mengaplikasikan Inventory management. Buku ini memberi panduan terhadap setiap langkah yang harus dilakukan mitra dalam mengaplikasikan Inventory management tersebut.

\section{KESIMPULAN DAN SARAN}

Sebagai sebuah organisasi skala Usaha Kecil dan Menengah (UKM) Sumber Berkat Mandiri yang berlokasi di Blitar, Jawa Timur memiliki potensi dan peluang yang besar dalam mengembangkan usahanya. Saat ini, UKM Sumber Berkat Mandiri telah mengembangkan usaha dengan menjual kurang lebih 350 jenis alat-alat peternakan, pertanian modern, dan teknik. Selain melayani pembeli yang datang ke toko, proses pemasaraan online melalui marketplace seperti Tokopedia dan Shopee merupakan salah satu upaya untuk mampu menjangkau konsumen lebih luas. Pentingnya membekali pimpinan dan karyawan mengenai Layanan Prima dan Etika Kerja dapat meningkatkan sikap peduli (care), berkomitmen terhadap tugas dan tanggung jawab serta antusias dalam menjalankannya. Pelatihan komunikasi interpersonal, manajemen waktu, dan kepemimpinan melengkapi soft skills para peserta pelatihan. Mereka jadi semakin menyadari kondisi UKM dan berusaha bersama untuk dapat lebih mengembangkan usahanya dalam satu kesatuan sebagai tim yang semakin solid. Sedangkan pelatihan penggunaan aplikasi inventory management memberikan bekal keterampilan dan kepiawaian menggunakan aplikasi yang sangat 
berguna dalam pencatatan inventori barang dagangan mereka.

Saran untuk UKM Sumber Berkat Mandiri:

1. Aplikasi akan berguna jika input dapat dilakukan dengan cermat, teliti, dan konsisten. Keberadaan aplikasi tersebut akan berdampak positif bagi kinerja UKM Sumber Berkat Mandiri jika pimpinan dan seluruh karyawan mau dan mampu menggunakan aplikasi tersebut secara konsisten.

2. Pelatihan softskills terkait layanan prima, etika kerja, komunikasi intepersonal, manajemen waktu, dan kepemimpinan juga harus diterapkan secara sungguhsungguh oleh pemilik dan para karyawan UKM Sumber Berkat Mandiri.

\section{DAFTAR PUSTAKA}

Haynes, Marion E. 1994. Manajemen Waktu untuk Diri Sendiri. Jakarta: Binarupa Aksara.

Jappi, Rosina \& Dianne Frisko Koan. 2014. "Penerapan Inventory Management dalam Meningkatkan Profitabilitas di Toko X Kupang". Jurnal Ilmiah Mahasiswa Universitas Surabaya. Volume 3 Nomor 1 (2014)

Sampson, Eleri. 2003. 101 Cara Memperkuat Kesan Profesional. Jakarta: Elex Media Komputindo.
Yuwono, Ismantoro Dwi. 2011. Memahami Berbagai Etika Profesi \& Pekerjaan. Yogyakarta: Pustaka Yustisia. 